\title{
The optimal transmission and dual resonant for different geometrical U-shaped THz nano antenna with surface plasmons (SPs) biosensors
}

\author{
Mohanad Aljanabi ${ }^{1}$, Ahmed Hussein Duhis ${ }^{2}$, Ahmed Obaid Aftan ${ }^{3}$, Nadia alanı ${ }^{4}$ \\ ${ }^{1,2,3}$ Electrical Power Techniques Engineering, Technical College /AL-Mausaib, Al-Furat Al-Awsat Technical University, \\ Iraq \\ ${ }^{4}$ Al-Musaib Engineering College, Iraq
}

\begin{tabular}{l}
\hline \hline Article Info \\
\hline Article history: \\
Received Mar 20, 2019 \\
Revised May 27, 2019 \\
Accepted Jul 27, 2019 \\
\hline
\end{tabular}

\section{Keywords:}

Biosensors

Dual-spectral resonances

FDTD

Nanoantenna

Plasmonic

\begin{abstract}
In this study, we focus on plasmonic nanoantenna structures for the $\mathrm{U}$ shaped. We will do our simulations with FDTD method (finite difference time domain) by considering commercial software Lumerical. We use U-shaped and play with the geometrical parameters such as length (L), width $(\mathrm{W})$, high $(\mathrm{H})$, to enhance the transmission of light. In addition to this, we will consider the different methods and substrates. U-shaped designed structure by using gold and $\mathrm{MgF} 2$ materials and studied how to enhance nanoantenna coefficients to get the highest electric field improvement factor and support dual-spectral resonances that can be changed from visible to near-IR wavelengths. For optimum coefficients, the proposed U-shaped nanoantenna reached the optimal transmission and multi-resonant for different geometrical size. In results shows that in this model are wideband range of wavelengths, optimal transmission and all physical border situations are selected to avoid undesired reflections. When we change the size of U-shaped with different materials is used and gets more proposes in the biosensors, biomedical, energy solar cells and laser optical communication. We can see that there are two resonances at $\left(\boldsymbol{\lambda}_{1}\right.$ and $\left.\boldsymbol{\lambda}_{2}\right)$ wavelength range $(500-950) \mathrm{nm}$, the first one has a transmission 0.73 at wavelength $700 \mathrm{~nm}$; and the other one has a transmission 0.88 at wavelength $845 \mathrm{~nm}$ from this designed. We will investigate the structure of nanoantenna to be used as biosensors.
\end{abstract}

Copyright $(0) 2020$ Institute of Advanced Engineering and Science. All rights reserved.

\section{Corresponding Author:}

Mohanad Aljanabi,

Electrical Power Techniques Engineering,

Technical College /AL- Mausaib, Al-Furat Al-Awsat Technical University, Najaf, Iraq.

Email: com.mhn@atu.edu.iq

\section{INTRODUCTION}

Researches study on Plasmonics since 1955 it had first discovered [1, 2]. Surface Plasmons (SPs) are collective oscillations of free electrons which are excited by light or photon [3-5], Plasmonics characterize a speedily growing field for the application of surface/interface plasmons near recognition of a variation of surface-Plasmon-based strategies counting: biosensors, PV, waveguides, data storage, Nano-imaging [3]. SPPs which lies between the interface of the dielectric and the metal as shown in Figure 1 and $2[6]$. 


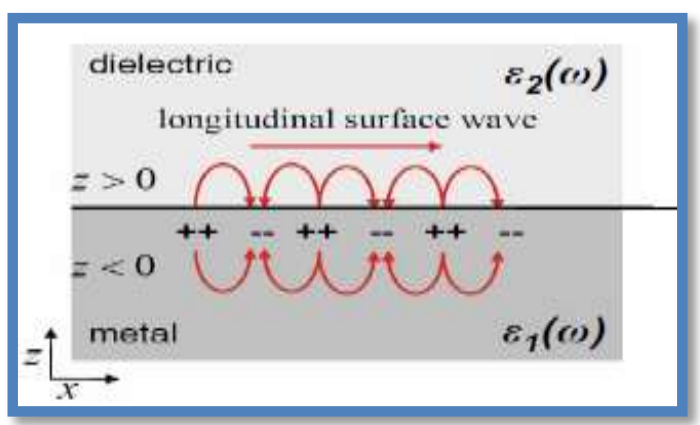

Figure 1. Diagram of SPPs at a metal-dielectric boundary [6]

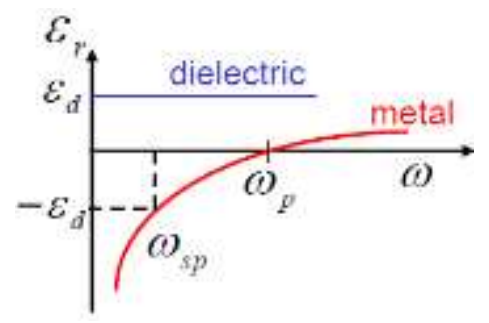

Figure 2. Shows Dispersion Relation Surface-Plasmon between dielectric and metal

The Lorentz equation of motion is:

$$
\begin{aligned}
& \vec{F}=m \vec{a}=m \frac{d^{2} x}{d t^{2}}=-q E \\
& x=\frac{q E}{\omega^{2} m}
\end{aligned}
$$

The dipole moment per unit volume, is:

$$
P=-n q x=-\frac{n q^{2}}{m \omega^{2}} E
$$

The dielectric function at frequency is:

$$
\begin{aligned}
& \varepsilon(\omega)=\frac{D(\omega)}{\varepsilon_{o} E(\omega)}=1+\frac{P(\omega)}{\varepsilon_{o} E(\omega)} \\
& \omega_{p}^{2}=\frac{n q^{2}}{\varepsilon_{o} m} \\
& \varepsilon(\omega)=1-\frac{\omega_{p}^{2}}{\omega^{2}} \\
& \varepsilon_{m}=1-\frac{\omega_{p}^{2}}{\omega^{2}}=-\varepsilon_{d} \\
& \omega=\omega_{s p} \\
& \omega_{s p}=\frac{\omega_{p}}{\sqrt{1+\varepsilon_{d}}}
\end{aligned}
$$


The nanostructured metals illustration multipart and optical possessions [7]. The properties of SPs based on the exact properties of together the metal and the insulator refractive index (n) [8-10], the disadvantage of sensing biomedical of low absorption, the difference in SPR angle is minor this reasons problems in distinguishing the developed signal [11-15].There are two reasons to make the SP resonance very sensitive and use it as a sensor, one it is a function of dielectric index and the second confinement of the sensing electromagnetic field to within about a wavelength of the surface [16, 17]. The biological applications and technologies deal with two types of plasmonic phenomena: LSPR and SERS [18- 21]. The biological sciences used gold nanoparticles or colloids to label organic substances or biological material primarily for electron microscopy, the gold has high difference compared to organic substances because of its electron density [22-24].

Theoretic and investigational outcomes check that $\mathrm{MgF} 2$ buffer layer with $\mathrm{n}=1.37$, with thickness (300-450) $\mathrm{nm}$ and $\mathrm{Ag}$ is equal to $40 \mathrm{~nm}$ may be used to tolerate at VIS wavelength for optical biological and chemical sensors [25-27]. The field optics is the basic of a principle of optical antenna, the first use of colloidal gold nanoparticles for optical radiation on a classical surface was appear in 1928 by Synge. [29] In 1985 Wessel utilized gold nanoantenna, Fischer et al. in 1995 was confirmed SPs by a gold-coated [30]. In 1997, bow-tie kind nanoantennas have been proposed as optical probes for the near-field [31]. Another type of nanoantennas known as dipole nanonantenna used in Active Photonic devices by Cubukcu, in 2006. [32] In $2008 \mathrm{Kim}$ developed nanoantenna for Non-linear spectroscopy after that in 2009 Kinkhabwala worked in Sensing field by bow-tie nanoantennas [33-35].

The optical properties of the Ag bowtie plasmonic nanoantenna structures on the $\mathrm{SiO} 2 / \mathrm{Si}$ substrate with and without MoS2 [36-38]. Recently, Turkmen, et al. have considered and invented changed sampling of nanoantenna for biosensor base on $\mathrm{SiN}$ with refractive index membrane [39, 40]. Also, Mosallaei et al. are designed the $\mathrm{Ag}$ based on $\mathrm{SiO}_{2}$ with $\mathrm{n}=1.45$ layer for plasmonic nano antenna [33].

Zarrabi, for demonstrating the sample structures, here $\mathrm{SiN}$ is selected for Substrate with $\mathrm{n}=1.98$ and silver [41]. YING et al. present-day a powerful technique to develop the MP resonances of metamaterials composed of 2D periodic arrays of $U$-shaped sliver when $n$ is varied from $(1.30-1.38)$ suspended by silica pillars on silica substrate for high-quality sensing applications in biomedical sensing [42].

In this study, use U shaped and play with the geometrical parameters to enhance the transmission of light and illustrate the optical properties for SPs metals and to determine from these limitations the disturbs geometry and figure on sensors applications and optoelectronic strategies. In addition to this shaped gold nanoantennas and $\mathrm{MgF} 2$ supports dual-resonances, and we will investigate the structure of nanoantenna to be used as biosensors.

\section{METHOD}

The model of $U$ shape nanoantenna is based $\mathrm{Au}$ on $\mathrm{MgF} 2$ substrate with refractive index $\mathrm{n}=1.36$, the geometrical parameters are illustrated in Figure 3 and 4. U nanoantennas in different sizes and shapes based on metal can work light at subwavelength array by SPs in metal. From the design the spectral response of the scheme has dual bands.

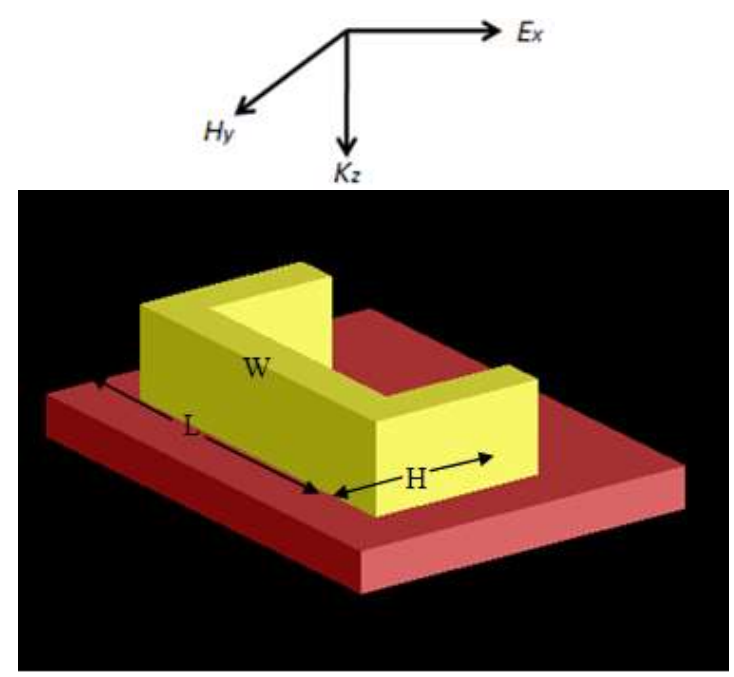

Figure 3. The representation U-molded nanoantennas design 
The technology of nano fabrication is introduced in different sizes and shapes that is a nano structure of Plasmonics based on metallic known as PRA (plasmonic resonator antennas) [43]. These structures are used in biosensing and surface enhanced spectroscopy. This observation indicates that the $U$ shaped with periodic array of $U$ shape show strong dependence on geometrical parameters.

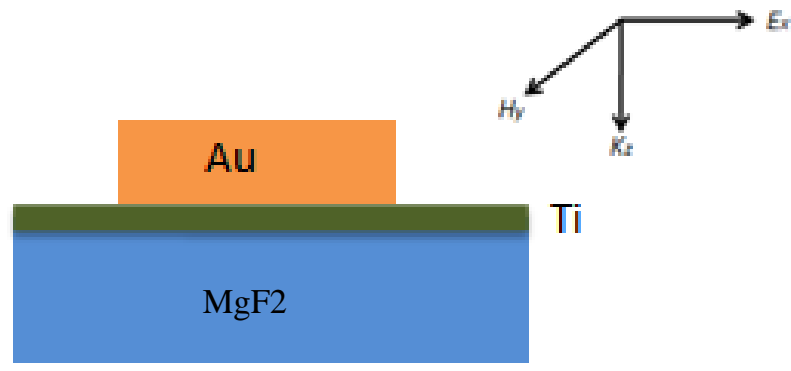

Figure 4. Schematic side view of proposed nanoantenna layers of $U$ shaped

Properties of optical nano antennas are strongly dependent on:

1) The geometrical design.

2) Material properties of the nanoparticles.

3) The surrounding medium, due to resonance of surface Plasmon.

\section{SIMULATION RESULTS AND DISCUSSION}

In this paper, we simulate FDTD to build a simulation of U shape nanoantenna with geometrical parameters are $(\mathrm{L}=600-800, \mathrm{H}=350-500, \mathrm{~W}=50-140) \mathrm{nm}$, thickness of $\mathrm{MgF} 2$ are range from (200 to 300 ) $\mathrm{nm}$ and gold is $100 \mathrm{~nm}$. The incident source in $\mathrm{z}$ dierction corresponding to perfectly matched layer (PML), for $\mathrm{x}, \mathrm{y}$ axis we used periodic boundary condition.

From Figure 5, we can see that there are two resonances at $\left(\boldsymbol{\lambda}_{1}\right.$ and $\left.\boldsymbol{\lambda}_{2}\right)$ wavelength range (500-950) $\mathrm{nm}$, the first one has a transmission 0.73 at wavelength $700 \mathrm{~nm}$; and the other one has a transmission 0.88 at wavelength $845 \mathrm{~nm}$. With same way we found the transmission response as shown in Figures 6, 7, 8, 9, 10 with different parameters. The position of resonances can be used and adjusted by changing geometrical constraints.

In the field of plasmonic structure design, they have been used to alter the resonant response of nanoparticles. In this method, the $U$ shaped nanoantenna performance becomes controllable by changing the values of these conditions, sizes and the optimization plan can be theoretically applied by further modification.

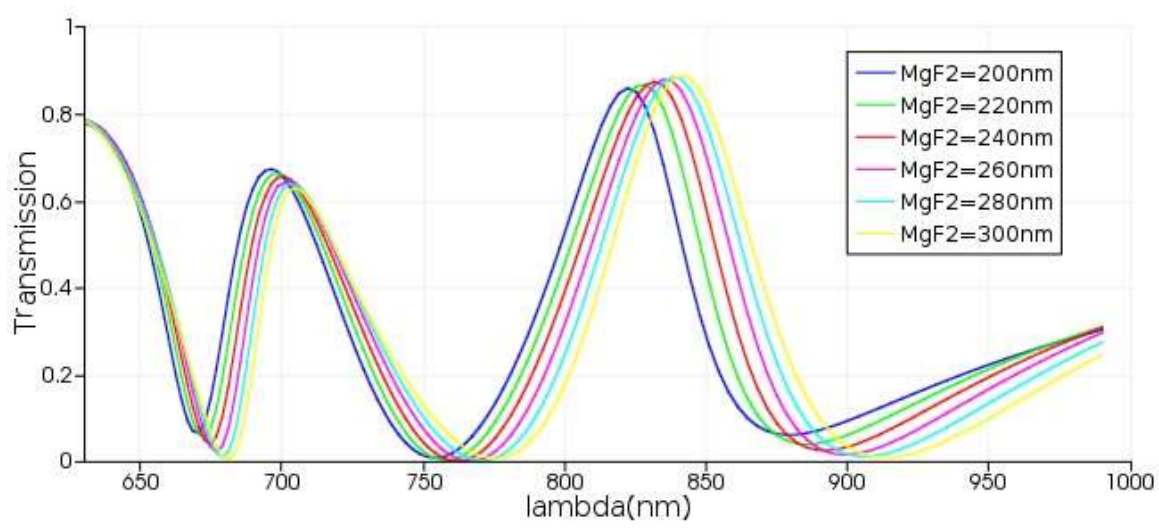

Figure 5. Dimensions of U-shaped nanoantennas with $\mathrm{L}=600 \mathrm{~nm}, \mathrm{H}=450 \mathrm{~nm}, \mathrm{~W}=100 \mathrm{~nm}$ with variation $\mathrm{MgF} 2$ 


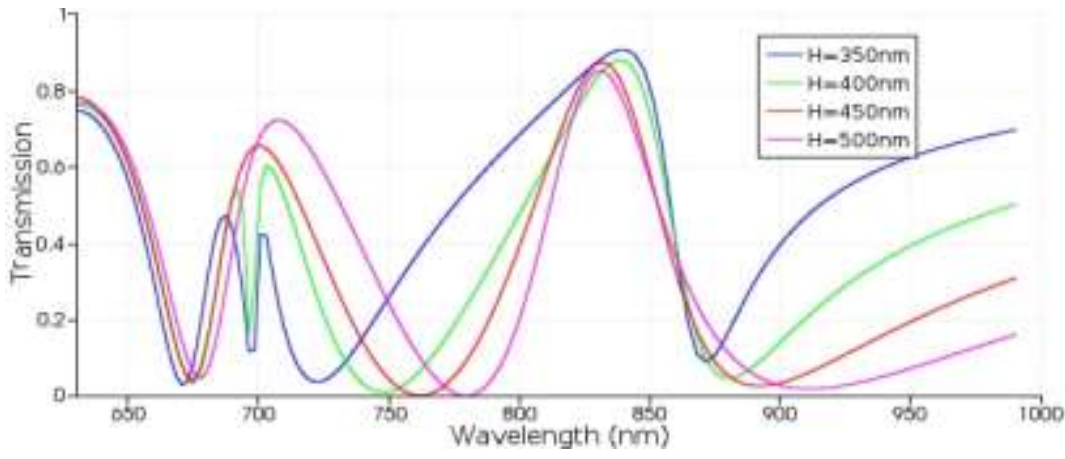

Figure 6. Dimensions of U-shaped nanoantennas with $\mathrm{L}=600 \mathrm{~nm}, \mathrm{MgF} 2=240 \mathrm{~nm}, \mathrm{~W}=100 \mathrm{~nm}$ with variation $\mathrm{H}$

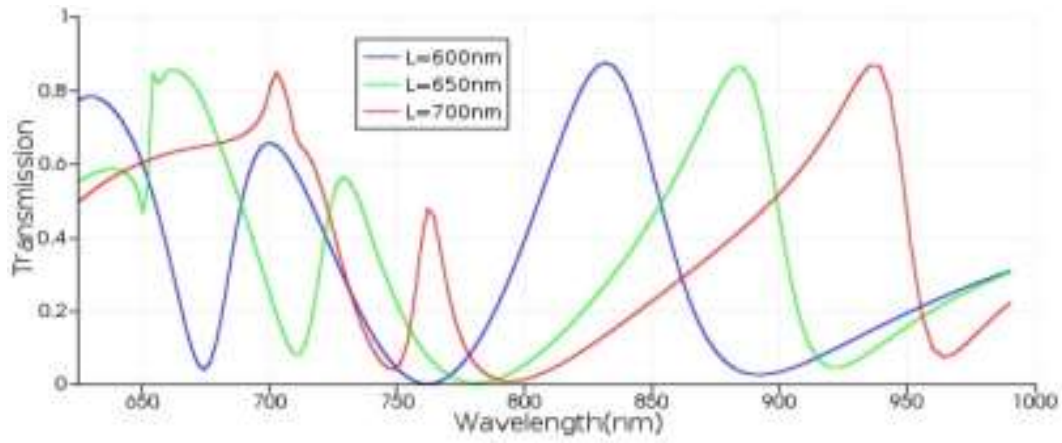

Figure 7. Dimensions of U-shaped nanoantennas with $\mathrm{H}=450 \mathrm{~nm}, \mathrm{MgF} 2=240 \mathrm{~nm}, \mathrm{~W}=100 \mathrm{~nm}$ with variation $\mathrm{L}$

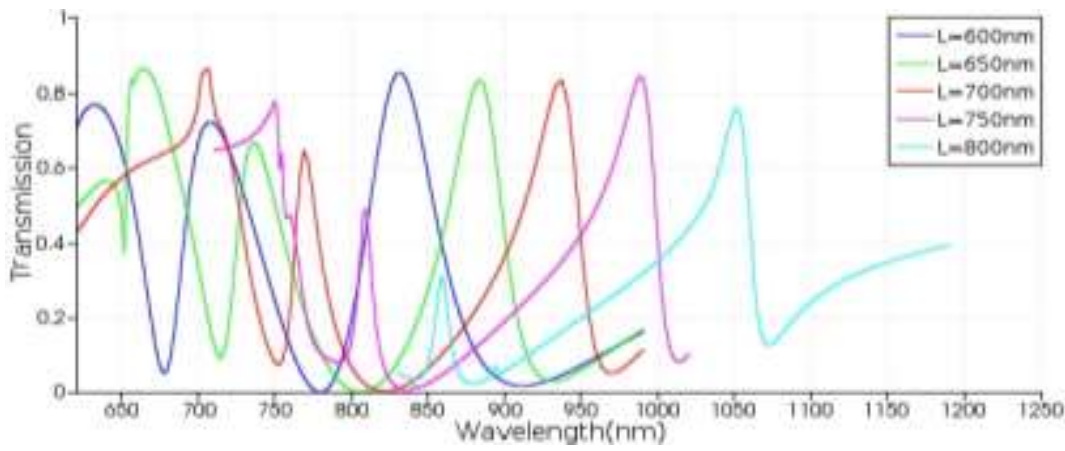

Figure 8. Dimensions of U-shaped nanoantennas with $\mathrm{H}=500 \mathrm{~nm}, \mathrm{MgF} 2=240 \mathrm{~nm}, \mathrm{~W}=100 \mathrm{~nm}$ with variation $\mathrm{L}$

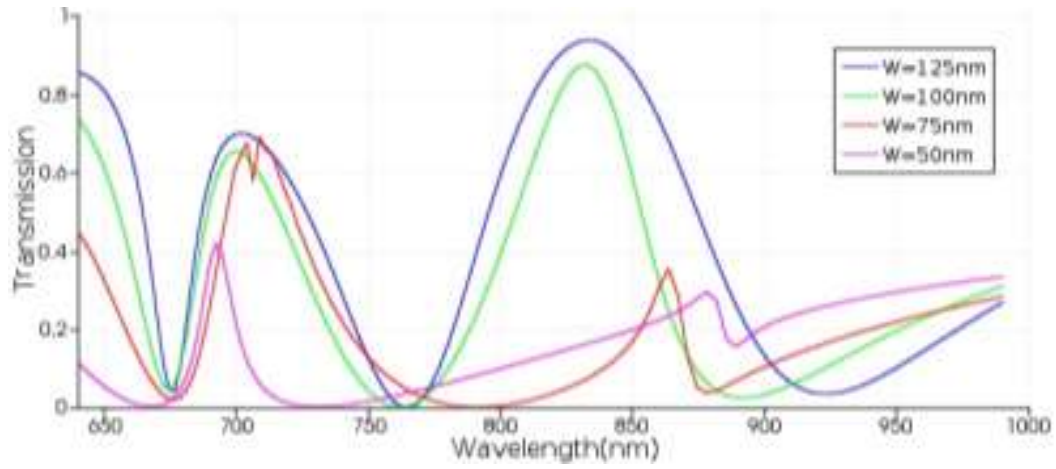

Figure 9. Dimensions of U-shaped nanoantennas with $\mathrm{H}=450 \mathrm{~nm}, \mathrm{MgF} 2=240 \mathrm{~nm}, \mathrm{~L}=600 \mathrm{~nm}$ with variation W 


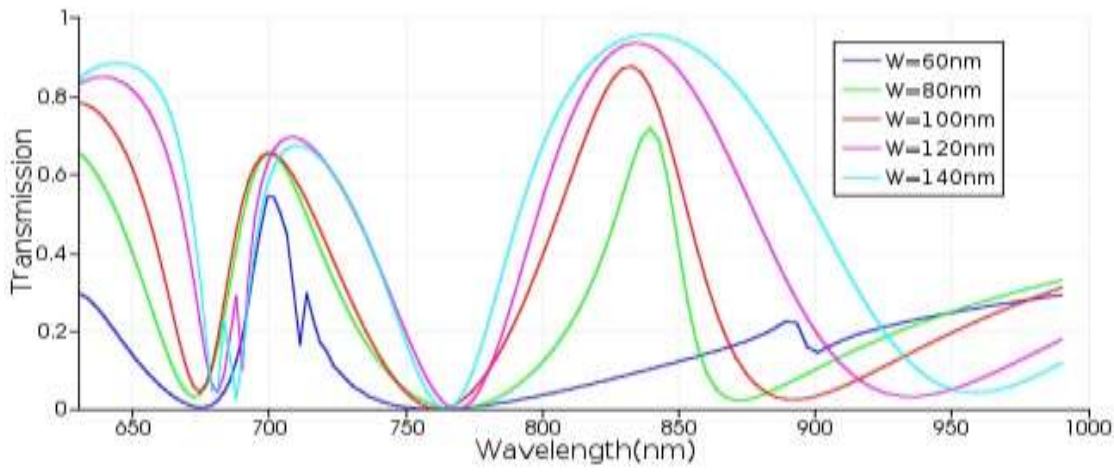

Figure 10. Dimensions of U-shaped nanoantennas with $\mathrm{H}=450 \mathrm{~nm}, \mathrm{MgF} 2=240 \mathrm{~nm}, \mathrm{~L}=600 \mathrm{~nm}$ with variation W

\section{CONCLUSION AND FUTURE WORK}

To conclude, geometrical dependency of resonances is calculated by altering $L, \mathrm{H}, \mathrm{W}$ and space gap (S) of the nanoantenna and it is realized that by enhancing both limitations, resonance wavelength tends shift. It is similarly silent that changing the gap height has the same outcome of changing the gap size and there is no notable change in dual bands because of change in these two constraints. Currently, the use of SPR in optical U-shaped nanoantennas types them more effective for designated frequencies of biosensors [36, 37].

There are two reasons to make the SPs very sensitive and use it as a biosensor, it is a function of dielectric index and the confinement of the sensing EM field to within about a wavelength of the surface. In conclusion, the plasmonic resonance is not individual delicate to the form and dimensions of a nanoantennas, correspondingly the dielectric intermediate surrounding the particle manipulates a main part.

\section{REFERENCES}

[1] S. A. Maier. "Plasmonics: Fundamentals and applications." Springer, New York, (2007).

[2] J. Zenneck, "Über die Fortpflanzung ebener elektromagnetischer Wellen längs einer ebenen Leiterfläche und ihre Beziehung zur drahtlosen Telegraphie,“ Ann. D. Phys. 23 pp846-866, (1907).

[3] R. H. Ritchie, Phys. Rev.106, pp. 874-881, (1957).

[4] B. Saleh and M. Teich." Fundamentals of Photonics. Wiley Series in Pure and Applied Optics.” Wiley, (2007).

[5] Atul Tiwari, Rabah Boukherroub, and Mahesh war Sharon "Solar Cell Nanotechnology" (2014).

[6] Jiri Homola, "Surface Plasmon Resonance (Spr) Biosensors and Their Applications in Food Safety and Security", Physics and Chemistry, vol 216. Springer. 2006.

[7] Ki Young Kim, “Plasmonics Principles and Applications”,ch2,pp82,(2012),

[8] Haes, A.J., and Van Duyne, R.P.: "A Nanoscale Optical Biosensor: Sensitivity and Selectivity of an Approach Based on the Localized Surface Plasmon Resonance Spectroscopy of Triangular Silver Nanoparticles", J. Am. Chem. Soc., 124,), pp10596-10604, (2002).

[9] R.B.M. Schasfoort and Anna J. Tudos," Handbook of Surface Plasmon Resonance", PP38, (2008).

[10] Shuwen Zeng," Nano materials enhanced surface Plasmon resonance for biological and chemical sensing applications" Chemical Society Reviews., August (2016).

[11] George K. Knopf, “Amarjeet S. Bassi, Biosensor Technology”, ch2, pp104, (2007).

[12] Xiaowei Guo, "Surface Plasmon resonance-based biosensor technique A review": Journal of Biophotonics, April (2012).

[13] D.A. Stuart, A.J. Haes, C.R. Yonzon, E.M. Hicks and R.P. Van Duyne, "Biological applications of localized surface plasmonic phenomena", IEE Proc.-Nanobiotechnol., Vol. 152, No. 1, February (2005).

[14] Link, S., and El-Sayed, M.A. "Spectral Properties and Relaxation Dynamics of Surface Plasmon Electronic Oscillations in Gold and Silver Nano-dots and Nano-rods", J. Phys. Chem. B, 103pp. 8410-8426, (1999),

[15] Mulvaney, P. "Surface Plasmon Spectroscopy of Nanosized Metal Particles", Langmuir12, pp788-800, (1996),

[16] DROR SARID AND WILLIAM A. CHALLENER” Modern introduction to surface plasmons pp322, (2010).

[17] S.O. Jung, H.S. Ro, B.H. Kho, Y.B. Shin, M.G. Kim and B.H. Chung, Proteomics, 5, pp4427, (2005).

[18] Diering er, J. A., et al., Faraday" Surface Enhanced Raman Spectroscopy, ch6, pp.132, (2006).

[19] Alvare z-Puebla, R. A., and Liz-Marzan, L. M., Energy Environ Sci (2010) 3(8), pp1011.

[20] K. A. Willets and R. P. Van Duyne.” Localized surface Plasmon resonance spectroscopy and sensing “. Annual Review of Physical Chemistry, 58: pp267-297, (2007).

[21] Nath, N., and Chilkoti, A.: "Immobilized gold nanoparticle sensor for label-free optical detection of bimolecular interactions”, Proc.SPIE-Int. Soc. Opt. Eng., 4626, pp.441-448, (2002). 
[22] Amir hossein Poursoltan mohammadi, M. chehel Amirani, Faghihi Faghihi, "Comparison of Shielding Effectiveness in Complex Curved Structure with Different Numerical Methods, FDTD, MOM and Equivalent Circuit", Indonesian Journal of Electrical Engineering and Computer Science (IJEECS), Vol 12, No 3: December 2018.

[23] Nurshamimi Rosli, Siti Aminah Md Akhir, Siti Zuraidah Ibrahim, Nur Baya Mohd Hashim, Nurehansafwanah Khalid, "Design of compact multi-mode microstrip resonator filters for dual-band application", Indonesian Journal of Electrical Engineering and Computer Science (IJEECS), Vol 13, No 2: February 2019.

[24] Stefan A. Maier, Yan Francescato, "New Frequencies and Geometries for Plasmonics and Metamaterials", (2014).

[25] Jeanmaire, D.L., Van Duyne, R.P. "Surface Raman spectroelectro chemistry. Part I. Heterocyclic, aromatic, and aliphatic amines adsorbed on the anodized silver electrode", J. Electro. Chem. Interfacial Electrochem., 84, pp1-20, 1977

[26] Alaa Farhood, Maham Kamil Naji, Suhad Hasan Rhaif Hasan Rhaif, Adnan Ali, "Design and analysis of dual band integrated hexagonal shaped microstrip UWB antenna," Indonesian Journal of Electrical Engineering and Computer Science (IJEECS), Vol 15, No 1: July 2019.

[27] Kneipp, K.; Moskovits, M.; Kneipp, H,” Surface-Enhanced Raman Scattering: Physics and Applications”, Eds.; Topics in Applied Physics 103; Springer: New York, (2013).

[28] C.R. Lavers, J.S. Wilkinson,” A waveguide-coupled surface-Plasmon sensor for an aqueous environment “, Sensors and Actuators, B22 (1994) 75-81.

[29] A. Sitt, I. Hadar, U. Banin, "Band-gap engineering, optoelectronic properties and applications of colloidal hetero structured semiconductor nanorods", Nano Today 8 (5) (2013) 494-513.

[30] M. Aidi, T. Aguili, "Electromagnetic modeling of coupled carbon nano tube dipole antennas based on integral equations system", Prog. Electromagnet. Res. M 40(2014) 179-183.

[31] J. Yang, F. Kong, K. Li, J. Zhao, "Optimizing the bowtie nano-antenna for enhanced Purcell factor and electric Field,” Prog. Electromagnet. Res. Lett. 44 (2014) 93-99.

[32] R. Filter, J. Qi, C. Rockstuhl, F. Lederer, "Circular optical nanoantennas: an analytical theory," Phys. Rev. B: Condens. Matter 85 (12) (2012) 125429.

[33] A. Ahmadi, H. Mosallaei, "Plasmonic nano loop array antenna," Opt. Lett. 35 (21) (2010) 3706-3708.

[34] J. Pérez-Juste, I. Pastoriza-Santos, L. M. Liz-Marzán, and P. Mulvaney, "Gold nanorods: Synthesis, characterization and applications," Coord. Chem. Rev. 249 (2005) pp.1870-1901.

[35] K. L. Kelly, E. Coronado, L. L. Zhao, and G. C. Schatz, "The Optical Properties of Metal Nanoparticles: The Influence of Size, Shape, and Dielectric Environment," J. Phys. Chem. B 107 (2003), pp.668-677

[36] C.-K. Chen, M.-H. Chang, H.-T. Wu, Y.-C. Lee, T.-J. Yen, "Enhanced vibrational spectroscopy, intracellular refractive indexing for label-free biosensing and bio imaging by multiband plasmonic-antenna array", Biosens. Bioelectronics. 60(2014) 343-350.

[37] H. I Malik, M. Y. Ismail, S. R Masrol, Sharmiza Adnan, "Reflection phase analysis of reflect array antenna based on paper substrate materials," Indonesian Journal of Electrical Engineering and Computer Science (IJEECS), Vol 13, No 2: February 2019.

[38] Lee, B., Park, J., Han, G., Ee, H., Naylor, C., Liu, W., Johnson, A. \& Agarwal, R. "Fano Resonance and Spectrally Modified Photoluminescence Enhancement in Monolayer MoS2 Integrated with Plasmonic Nanoantenna Array". Nano Letters 15, 3646-3653 (2015)".

[39] Ibtissame Moumane, Jamal Zbitou, M. Latrach, A. Errkik, O. Chakkor, “A novel configuration of THz photonic transmitter", Indonesian Journal of Electrical Engineering and Computer Science (IJEECS), Vol 13, No 1: 2019.

[40] A.E. Cetin, M. Turkmen, S. Aksu, D. Etezadi, H. Altug, "Multi-resonant compact nano aperture with accessible large near fields", Appl. Phys. B 118 (1) (2015), pp.29-38.

[41] F.B. Zarrabi, "Sub wavelength plasmonic nano-antenna with $\mathrm{H}$ and $\mathrm{U}$ shape for enhancement of multi resonance," Optik - Int. J. Light Electro Opt. (2016)’http://dx.doi.org/10.1016/j.ijleo.2016.01.189.

[42] Iraj Sadegh Amiri, Ahmed Nabih Zaki Rashed, "Numerical investigation of V shaped three elements resonator for optical closed loop system", Indonesian Journal of Electrical Engineering and Computer Science (IJEECS), Vol 16, No 3: December 2019.

[43] A. V. Kabashin, P. Evans, S. Pastkovsky, W. Hendren, G. A. Wurtz, R. Atkinson, R. Pollard, V. A. Podolskiy, A. V. Zayats, "Plasmonic Nanorod Metamaterials for Biosensing," Nature Materials 8, 867 (2017). 